\title{
CHALLENGES OF REMOTE SENSING AND SPATIAL INFORMATION EDUCATION AND TECHNOLOGY TRANSFER IN A FAST DEVELOPING INDUSTRY
}

\author{
F. Tsai* and L.-C. Chen \\ Center for Space and Remote Sensing Research, National Central University \\ 300 Zhongda Road, Zhongli, Taoyuan 320 Taiwan \\ \{ftsai, lcchen\}@csrsr.ncu.edu.tw
}

KEY WORDS: Higher Education, Technology Transfer, Capacity Building, Geospatial Curriculum

\begin{abstract}
:
During the past decade, Taiwan has experienced an unusual and fast growing in the industry of mapping, remote sensing, spatial information and related markets. A successful space program and dozens of advanced airborne and ground-based remote sensing instruments as well as mobile mapping systems have been implemented and put into operation to support the vast demands of geospatial data acquisition. Moreover, in addition to the government agencies and research institutes, there are also tens of companies in the private sector providing geo-spatial data and services. However, the fast developing industry is also posing a great challenge to the education sector in Taiwan, especially the higher education for geo-spatial information. Facing this fast developing industry, the demands of skilled professionals and new technologies in order to address diversified needs are indubitably high. Consequently, while delighting in the expanding and prospering benefitted from the fast growing industry, how to fulfill these demands has become a challenge for the remote sensing and spatial information disciplines in the higher education institutes in Taiwan. This paper provides a brief insight into the status of the remote sensing and spatial information industry in Taiwan as well as the challenges of the education and technology transfer to support the increasing demands and to ensure the continuous development of the industry. In addition to the report of the current status of the remote sensing and spatial information related courses and programs in the colleges and universities, current and potential threatening issues and possible resolutions are also discussed in different points of view.
\end{abstract}

\section{INTRODUCTION}

The use and awareness of geo-spatial information technologies and applications is increasing steadily during the last decade. The reason for this trend is manifold and can be attributed to a few factors. First of all, the advances of remote sensing and spatial information technologies have significantly reduced the cost of data acquisition, while the evolution of internet and information technologies for spatial information applications and services have also improved the availability and utilization of spatial data to general public. Secondly, according to a World Bank study (Dilley et al., 2005), the geographic location, geological conditions, and the social-economical complexity have made Taiwan one of the most vulnerable regions to natural disasters. Truly and tragically, a few catastrophic natural and non-natural disasters that took place in the region thus have also raised the public awareness of the remote sensing and spatial information technologies for hazard investigation, management and mitigation.

In general, the evolution of related technologies and the increasing demands of geo-spatial data, applications and services have fueled the prosperity of remote sensing and spatial information industry. However, in spite of the versatility and wide range of remote sensing and spatial information technologies, there is no one-fits-all or universal solution for the diversified market (Sinton, 2009). While enjoying the prosperity, the industry has started to suffer from its own success, partly because of fierce competition and partly due to the lack of effective technical support from the educational sector.

As a result and similar to other regions (Bian and Wang, 2008; Chaudhary, 2012; Lisec and Fras, 2012), on the one hand disciplines related to remote sensing and spatial information in the higher education universities or colleges in Taiwan have benefitted from the fast growing industry. On the other hand, how to develop a valid curriculum and effective technology transfer strategy to support the increasing demands of the fast developing spatial information industry has become a challenge for higher education institutes.

\section{CURRENT STATUS}

\subsection{A fast developing geospatial industry}

The capacity of remote sensing and spatial information industry in Taiwan is diversified. In terms of data acquisition instruments and service providers, it includes space, airborne, and groundbased sensors. The most prominent sensor is the FORMOSAT-2 earth observing satellite operated by the National Space Organization (NSPO). FORMOSAT-2 was launched in 2004. It has an unique daily-revisiting capability to image the earth surface with a panchromatic and multi-spectral sensor at a nominal ground resolution of 2 meters and 8 meters, respectively. The Satellite Receiving Station of CSRSR, NCU was established in 1990. It has the capability to receive and process data from multiple earth observing satellites with a ground coverage of $3,000 \mathrm{~km}$ in radius (Figure 1). Over the decades, the CSRSR ground station has been receiving, processing and archiving countless images from a variety of satellites, including SPOT 1-6, FORMOSAT-2, Landsat 5 and 7, EROS-A, ERS-1 and 2, MODIS (Terra and Aqua), and others. Together with other commercial and non-commercial satellite data providers, this space sector has supported various researches and applications of remote sensing and spatial information in Taiwan and nearby regions.

The market of airborne geospatial information industry in Taiwan is extremely competitive. There are 8 fixed-wing air crafts and two helicopters dedicated for aerial surveying and imaging in Taiwan. Table 1 and 2 briefly summarize the 7 large-format digital aerial cameras and 6 airborne LiDAR sensors that are actively in operation in Taiwan. As listed in the tables, the equipments are all 


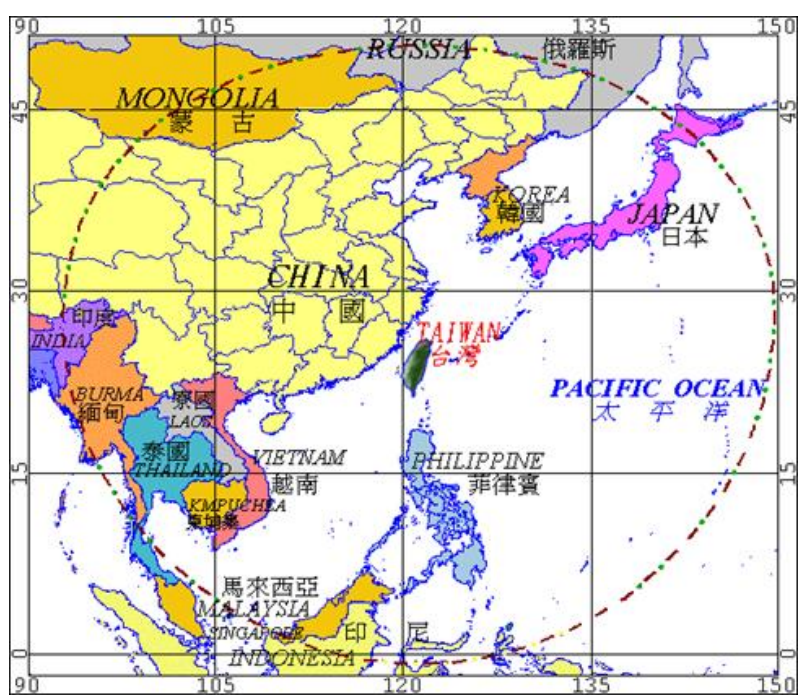

Figure 1: Reception coverage of the Satellite Receiving Station in CSRSR, NCU, Taiwan.

state-of-the-art models that provide robust data acquisition capability. There is also an airborne Synthetic Aperture Radar (SAR) system under development and will soon be deployed. The number of sensors may not seem high. However, these equipments are primarily, if not always, operated in Taiwan, with an area coverage of around $36,000 \mathrm{~km}^{2}$, which is about $1 / 265$ of the United States. According to an industry whitepaper about global LiDAR sensor market, up to 2009 about 300 airborne LiDAR units were sold worldwide and half of them were sold in the United States (Young, 2009). Therefore, the number of airborne LiDAR equipments in Taiwan is actually disproportionate comparing to the rest of the world and the same conclusion also applies to the aerial cameras, MMS, and UAV/UAS as described previously and later.

Table 1: Large format digital aerial cameras in Taiwan

\begin{tabular}{ccc} 
Type & Units & Remarks \\
\hline \hline Ultracam & 3 & 3 different models \\
ADS & 1 & \\
DMC & 3 & 3 different models
\end{tabular}

Table 2: Airborne LiDAR equipments in Taiwan

\begin{tabular}{cc} 
Make/Model & Remarks \\
\hline \hline Leica ALS50 & $65 \mathrm{kHz}$ \\
Optech ALTM 370 & $70 \mathrm{kHz}$ \\
Optech ALTM Gemini & $167 \mathrm{kHz}$ \\
Optech ALTM Orion & $200 \mathrm{kHz}$ \\
Leica ALS60 & $200 \mathrm{kHz}(\mathrm{MPiA})$ \\
Riegl LMS-Q680i & $400 \mathrm{kHz}(\mathrm{MPiA})$ \\
\hline
\end{tabular}

Similar trend is also happening in the ground-based sector of the industry, including mobile mapping systems (MMS) and unmanned aviation vehicles/systems (UAV/UAS). For example, there are more than 15 MMS vehicles roaming in the streets in Taiwan. The hardware and software configurations of these MMS platforms are diversified, too; ranging from commercial setups from well-known vendors (such as TOPCON, Riegl, Optech, and IWANE) to home-developed proprietary systems. In addition, there are also many IT and spatial information firms that provide geospatial data and services. In summary, the geospatial industry in Taiwan is fast developing and prosperous and it has also created significant impacts on different prospects, especially the higher education for photogrammetry, remote sensing and spatial information sciences.

\subsection{Higher education in related disciplines}

The undergraduate and higher educations of geoinformatics are loosely affiliated with multiple disciplines in colleges, universities, and institutes in Taiwan. The affiliations include engineerings, earth sciences, natural resources, environmental studies etc. and a few fields in social science, such as land economics, planning and development.

An unofficial survey conducted by the Chinese (Taipei) Society of Photogrammetry and Remote Sensing (CSPRS) concluded that from 1970 to 2010, the number of departments or institutes in colleges and universities offering related coursed in undergraduate or postgraduate levels along with the number of courses and credits have increased steadily and are still increasing. There was only one department, among all colleges and universities in Taiwan, offering courses in 1970 and the number has increased to 30 in 2010, as displayed in Figure 2.

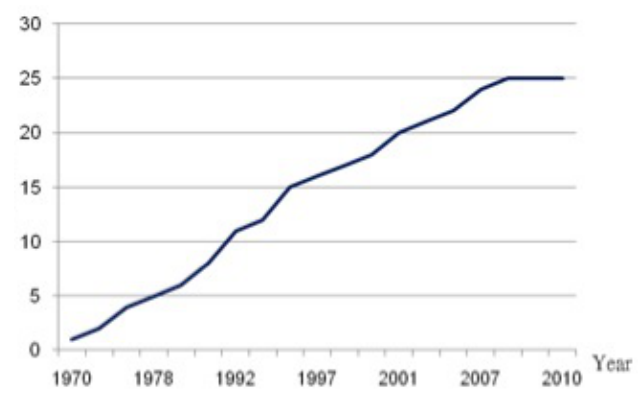

(a) Undergraduate

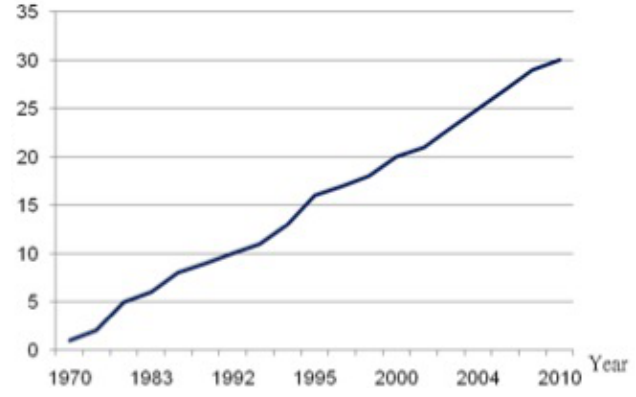

(b) Postgraduate

Figure 2: Number of departments offering geospatial courses.

The number of undergraduate courses has increased from 2 to 57 and the credits have increases from 6 to 162 as shown in Figure 3. For postgraduate courses, the number of courses changed from 2 to 89 while the total courses credits increased from 6 to 258 , as plotted in Figure 4. The curricula include different levels of the geospatial triad, or the so-called 3S-Remote Sensing (RS), Geographic Information Systems/Sciences (GIS), and Global Navigation Satellite Systems (GNSS)-from fundamental and introductory courses to advanced topics.

Given the scale of the market in the region, the curricula mentioned above may seem to cover most of the aspects to support the industry. Nevertheless, the real situation is that they are far from being adequate. Part of the reason for this inadequacy can be attributed to the evolving technologies and the fast developing industry. A more fundamental issue, however, lies heavy on the structure of the higher education system in Taiwan and the inefficient conduit of technology transfer, which causes a noticeable gap between the two sectors (industry and education). 


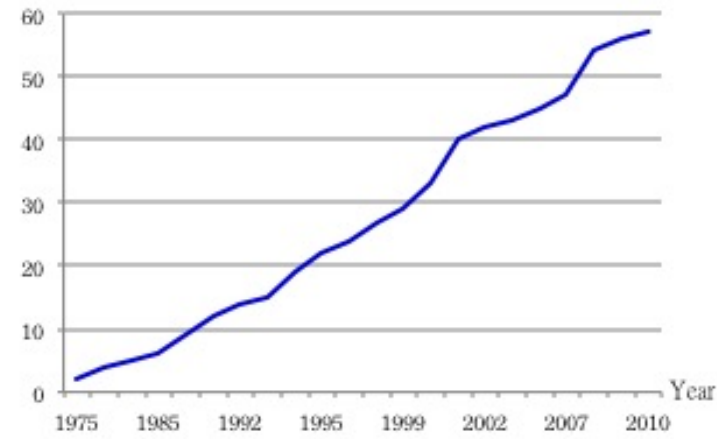

(a) number of courses

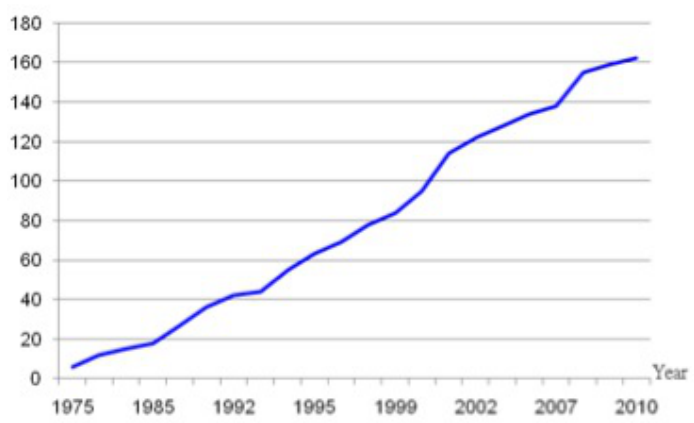

(b) number of credits

Figure 3: Number of undergraduate courses and credits

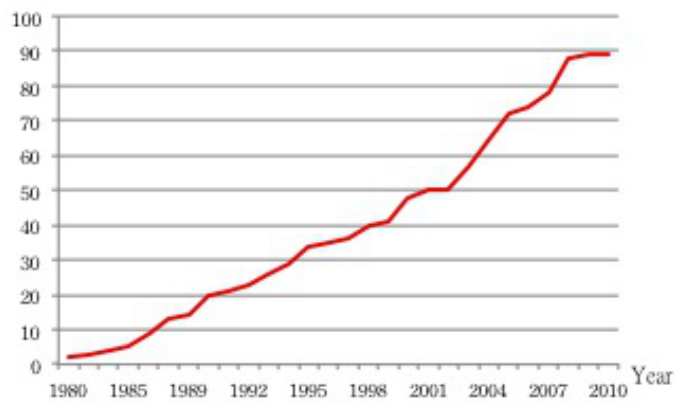

(a) number of courses

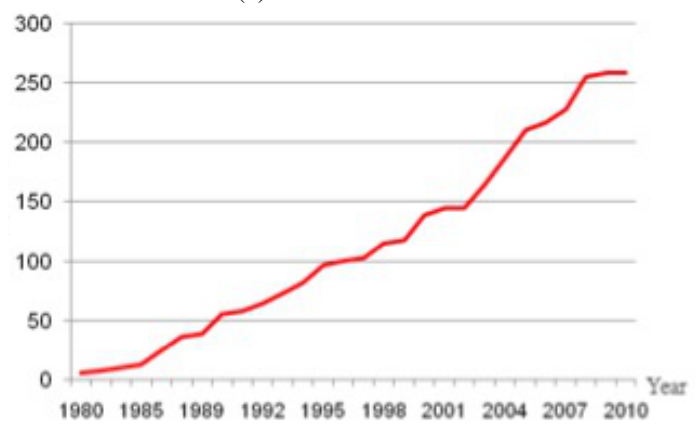

(b) number of credits

Figure 4: Number of postgraduate courses and credits

\section{ISSUES AND RECOMMENDATIONS}

The geospatial industry itself has several issues. First of all, hazard mitigation and related tasks are one of the main forces that drives the fast development of geospatial researches and applications in Taiwan. They are also the primary incentive motivating the private sector of geospatial industry to invest heavily on the new equipments for data acquisition. In terms of satellite-based data sources, other than the FORMOSAT-2, all the rest satellite imagery sources, commercial or non-commercial, are controlled by foreign providers and only a small portion of them can be obtained (received by a ground station) directly in Taiwan. For this reason, the demand of FORMOSAT-2 data has always been high in Taiwan. However, FORMOSAT-2 has already been beyond its designed life cycle, but its successor (FORMOSAT-5) will not be launched until 2015. Therefore, the continuity and stability of space-borne geospatial data is one of the major concerns in the industry.

Secondly, as mentioned previously, one of the reasons that some private enterprises in Taiwan invested heavily on the platforms and equipments is driven by the vast data acquisition demands after several natural hazards happened in the last decade. For example, most of the airborne LiDAR equipments were acquired for a large-scale digital terrain surveying for geohazards initiative after the catastrophic landslide in Southern Taiwan triggered by the heavy rainfall of Typhoon Morakot in 2009. Similarly, the overwhelming "arm race" on MMS and UAV both stem from the demands for special road inventory surveying and digital city modeling. Without these special projects, the routine mapping and inventory update tasks can not support the market with so many high-end equipments. The result is inevitable-to survive in the vicious market, "cut-throat" competition has become a common strategy and sometimes unethical lobbying and practice were employed. Consequently, exploring the new territory and developing a "blue ocean" strategy to enter the international market, is a must for the geospatial industry to continue its prosperity or even survive in the long rum.

The issues in the education sector are also complicated. Put aside the factors posed by the industry sector; there are concerns in the higher education system itself. Some of the issues are systemwide, not unique to the spatial information disciplines; but some of them have more significant impact on these fields. For example, most of departments and institutes in Taiwan are facing a serious decline of $\mathrm{PhD}$ students. In geoinformatic disciplines, part of the reason is that the healthy job market has reduced the incentive of prospective students to pursue a higher degree and enroll into a $\mathrm{PhD}$ program. Most of universities in Taiwan have embarked on recruiting international students to fill the vacancy left by domestic students, but the effect is limited to the best. In some departments, the recruiting of new faculty members is also facing certain degree of difficulty. Although some institutes offer All-English programs, the majority of postgraduate and all undergraduate courses are taught in Mandarin Chinese. This significantly limits the candidates of new faculty members to Chinesespeaking scholars. Given the limited number of institutes offering $\mathrm{PhD}$ degrees and the decline of $\mathrm{PhD}$ students (both studying locally or overseas), inbreeding is a potential problem and will become more and more serious. A full internationalization might be a possible solution to these issues, but it does not expect to happen in the near future.

In terms of the geospatial curricula, although the courses offered by the departments and institutes in colleges and universities cover a wide range of photogrammetry, remote sensing and spatial information sciences, most of the courses in the curricula focus on its concentrations. Unlike course curricula designed for K-12 education, which usually focus on introductory level and aimed for raise the awareness of geospatial techniques and possible applications (Ito et al., 2012), curricula in higher education, especially advanced courses for postgraduate study, tend to be "researchoriented" and may not be able to provide adequate practical training and inter-discipline knowledge, especially the integration of different domain knowledge.

This issue is uncommonly serious in the higher education system 
in Taiwan. Due to a strange education reform, most of short-term technical colleges or schools in Taiwan were converted to full universities, resulting in more than 160 universities in a region with a population of only twenty three millions. With the cultural stereotypes of scholars and professionals, curricula originally designed for training skilled professionals were subsequently changed to scholarly studies in almost all departments. This has created a gap between the industry and the education sectors. The industry expects graduates to acquire skills necessary for a given job and its tasks, but a college or university curriculum usually does not have the balance of knowledge acquisition and professional training. Some institutes started to develop short-term programs, such as capacity-building workshops, training courses, and so on for international and local students and young professionals (Tsai et al., 2010), but they are not common and still can not satisfactorily meet the demands. A better solution may be to create "certificate programs" and clearly distinguish them from the regular degree programs with tailored curricula.

\section{CONCLUSION}

This paper provides an overview of the current status and brief insights into the issues in the fast developing geospatial industry and higher education in Taiwan. The industry sector has enjoyed a prosperous market and steady growth during the last decade. In addition to a successful space program, various state-of-the-art airborne and ground-based remote sensing and spatial information systems were acquired and implemented to support the vast demands of data acquisition as well as diversified applications and services. The higher education sector also benefitted from the growing market with increasing coverage of curricula. However, while enjoying the prosperity, potential challenges have started arising both in the fast developing industry and in the education sector. In addition to the problems and issues described in this paper, there are other issues in the spatial information industry and education in Taiwan. The ones discussed here are either urgent or unique to the special social-cultural circumstances in Taiwan. The recommendations proposed in this paper may not all practi- cal or need significant efforts to accomplish, but they may provide possible solutions to the potential challenges in a fast developing geospatial industry and higher education.

\section{References}

Bian, F. and Wang, S., 2008. Problem, innovation, and development of GIS higher education in our country. International Archives of the Photogrammetry, Remote Sensing and Spatial Information Science XXXVII(B6a), pp. 269-272.

Chaudhary, B. S., 2012. Issues and challenges in geomatics eduacation in Haryana State, India. International Archives of the Photogrammetry, Remote Sensing and Spatial Information Science 39-B2, pp. 37-40.

Dilley, M., Chen, R. S., Deichmann, U., Lerner-Lam, A. L. and Arnold, M., 2005. Natural disaster hotspots: A global risk analysis. Technical report, World Bank.

Ito, Y., Teramoto, Y. and Abe, K., 2012. Development and evaluation of technology education using earth observation technique. International Archives of the Photogrammetry, Remote Sensing and Spatial Information Science 39-B2, pp. 13-18.

Lisec, A. and Fras, M. K., 2012. Higher eduacation in Balkan region and its contribution to the earth observation. International Archives of the Photogrammetry, Remote Sensing and Spatial Information Science 39-B2, pp. 72-77.

Sinton, D. S., 2009. Roles for GIS within higher education. Journal of Geography in Higher Education 33, pp. S7-S16.

Tsai, F., Shih, T. Y. and Chen, C. F., 2010. Multi-level geoinformation capacity building programs for domestic and international training in Taiwan. International Archives of the Photogrammetry, Remote Sensing and Spatial Information Science 38-part6, pp. ?

Young, J., 2009. LiDAR trends and developments. 